International Journal of Psychological Research and Reviews

\title{
Reactive depression in a sacro coccygeal chordoma
}

\section{Ndiaye-Ndongo Ndèye Dialé, Fall Lamine, Sylla Aïda, Thiam Mamadou Habib.}

Service de Psychiatrie du CHNU Fann, Dakar-Sénégal

\begin{abstract}
The association of depression and organic diseases is frequently described. Several authors have been interested in analyzing the links between the two entities. Depression is considered the dominant mode of reaction to somatic disorders. It is all the more frequent and marked that the disorder is life-threatening, painful, disabling. In this work, we report a reaction depression occurring in a patient with a sacro-coccygeal chordoma which is a relatively rare malignancy, with a reserved prognosis, revealed by common radiculalgia of appearance. This one required a care in Psychiatry parallel to the surgery. We emphasize the interest and the need for a multidisciplinary management framework.
\end{abstract}

\section{Keywords:}

depressive disorders; somatic affection; sacro-coccygeal mass
*Correspondence to Author:

Ndiaye-Ndongo Ndèye Dialé

Service de Psychiatrie du CHNU

Fann, Dakar-Sénégal

How to cite this article:

Ndiaye-Ndongo Ndèye Dialé, Fall Lamine, Sylla Aïda, Thiam Mamadou Habib.Reactive depression in a sacro coccygeal chordoma. International Journal of Psychological Research and Reviews, 2019, 2:7

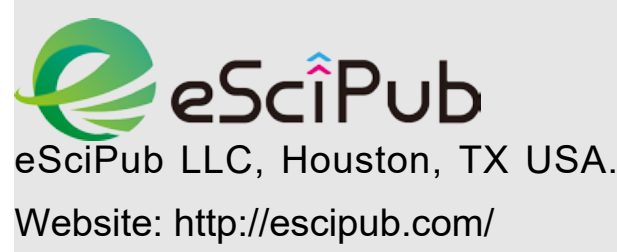




\section{Introduction}

Depression is often overlooked or poorly considered in patients with somatic disease. It is often regarded as a normal reaction to the disease and therefore minimized in relation to the healing sought by caregivers.

However, it can promote the aggravation or chronization of the physical illness. It can also increase the socio-professional handicap or be at the origin of rupture of care and sometimes of suicidal behavior. The nature of the relationship between depression and somatic illness is not univocal. It can be a simple coincidence, a direct influence of the physical disease through biological disturbances or a reactional depression to the consequences of the disease and to the hazards of its evolution. In many cases the causalities are intricate, more circular than linear.

We report the clinical observation of a patient who was referred to us by the Internal Medicine Department of the University Hospital Aristide Le Dantec where she was received for lumbar pain. Physical examination and exploration revealed a malignant tumor of the lumbar region. The circumstances of discovery and the context contributed to the psychic trauma in the patient who presented a denial and mood depression.

This work was also an opportunity to show the narrowness of somato psychic implications and to insist on holistic care

\section{Observation}

Mrs. S.G is a 58-year-old Senegalese woman, referred by internal medicine where she was received for lumbar pain lomboradiculalgies of common appearance, which were "trivialized" for about 13 months.

His orientation in psychiatry was motivated by a state of sadness with lamentations, incessant tears and total disinterest.

There is no personal psychiatric history. He is not found in his family.
The disorders began months before his consultation in Internal Medicine by lower back pain.

The pretext for her consultation was the preparation of a pilgrimage she wished to accomplish, she said, without any difficulty.

Thus, the patient repeated, insistently, throughout the consultation in medicine: "It's nothing serious but given my trip, I just want sedatives to be able to perform well the pilgrimage."

The physical examination objectified a mass of the right buttock. Magnetic resonance imaging revealed a large lesion centered on the sacrococcygeal region.

Mrs. SG was then informed of the need to explore this mass discovered on the MRI. Her first reaction was to say that the doctors had to be mistaken for clichés because she had nothing.

Several interviews were followed with the support of her husband to complete the explorations with a biopsy of the lesion and an anatomo-pathological examination.

Anatomo-pathological examination of the mass, after biopsy, was in favor of sacro-coccygeal chordoma. In other words, a malignant tumor. Diagnosis very surprising for her.

This was the beginning of a refusal of any treatment, of total disinterest.

It was during his check-up that the husband told the treating doctor about behavioral disorders. It is then addressed to us.

At the psychiatric examination, the mimicry is poor, frozen doing pain. The eyes are haggard with a staring, terrified look. The barely audible answers are made of bits of words interspersed with sighs. His words reflect the discouragement: "I will not heal, let me go." She adds, "You can not do anything for me, I'm going to die." She gets up sometimes and goes to the door to leave. When she sits down pulled by her husband, she reports: "I left just for sedatives." She adds: "I had nothing, I had to make my pilgrimage, that I waited all my life". 
She does not sit constantly trying to get up with difficulty to leave, movements interrupted by her husband. She looks worriedly around her. The mood is sad with ruminations anxious about his illness: "They tell me that I have cancer, they have done all kinds of exams." The interview is interrupted by long silences and crying. The husband reports non-selective anorexia, sleeping disorders such as sleeponset insomnia and early awakening. What Mrs. SG says, "How to sleep when you're waiting for death all the time"

There are ideas of incurability, of death: "My illness is incurable, I am going to die, let me go."

The husband reports that Mrs SG begins to lock herself in her room, crying for hours. She does not eat anymore, does not go out anymore. She does not take care of anything in the house anymore. Nothing makes him more happy.

This depressive picture occurred in the days following the announcement of the explorations to be made with the radiological discovery correlated with the clinic. It intensified with the announcement of the causal affection, cancer.

\section{Discussion}

Sacro-coccygeal chordoma is a rare malignant bone tumor derived from an attack of the notochord, described for the first time by Wirchow in 1857 [1]. In 1858, Muller specified its notochordal origin [2]. It represents 1 to $4 \%$ of bone tumors; sacro-coccygeal localization is one of the most frequent, especially between the 4th and 6th decades, whereas sphenooccipital localization is frequent in children and adolescents. Because of its pauci-symptomatic character, the diagnosis is often delayed until the stage of complications [3].

The age of our patient, 58 years old, is consistent with literature data that place sacrococcygeal chordomas after 50 years $[4,5]$. The diagnostic delay in our patient was one year with locoregional invasion at the time of diagnosis. Indeed, chordomas are characterized by a very slow evolution and little symptomatic, source of a significant diagnostic delay between 12 and 24 months [6].

The mass found at the upper part of the right buttock is related to right gluteal invasion confirmed by MRI. However, the patient had no gastrointestinal or urinary symptomatology despite the endo-pelvic invasion found on MRI. The anatomo-pathological examination, indispensable to the diagnosis, confirmed sacro-coccygeal chordoma. The sacrococcygeal chordomas remain a diagnostic possibility, certainly rare, but possible in front of any picture of lomboradiculalgia of common appearance after 50 years.

\section{Circumstances of discovery and the experience of Ms. SG}

Such circumstances may seem a priori sufficient to explain depression, but should not preclude further analysis of living conditions.

The depressive disorders observed in medical conditions are usually of moderate intensity, sometimes transient [7]. The role of organic diseases in the genesis or maintenance of these depressive disorders is variously estimated according to the studies, but seems generally important [8].

Depressive states and somatic diseases associate more frequently than mere chance would. This co-occurrence has long been the source of many theoretical and practical questions that are far from being resolved. For some, this aggregation phenomenon occurs readily in vulnerable individuals during periods of environmental stress [9]. We did not find any arguments in MS for the diagnosis of pathological personality. Thus the pathogenic character of the psychological trauma constituted here by the disease is less related to the event in its objectivity than to the context of discovery. And so what does this cancer represent in Mrs. SG's emotional investments? Depression seems linked to an emotional and emotional exhaustion due to a stress summation, to a situation of psychic trauma, 
where the patient abruptly discovers the reality of her death, with fright and surprise.

Indeed, stress states and depression are associated with high levels of adrenaline and cortisol that are inversely related to immune function [10].

\section{Conclusion}

The study of this case showed us how the psychological state of a subject is determining in the evolution of a health disorder.

It also allowed us to see that any organic condition is potentially depressogenic. Depression is often linked to the suffering, to the experience of the illness but also to the context of occurrence.

We have realized that the role of somatic specialists is important in detecting depressive disorders. Multidisciplinary care should not be split, each specialist working on his side, but should also involve constant communication between the various stakeholders. Because being the best equipped to inform or reassure the patient in relation to his disorder.

It will then be a holistic care, considering the suffering person as a whole.

\section{References}

1. Heaton JM, Turner DR. Reflections on notochordal differentiation arising from a study of chordoma. Histopathology 1985; 9: 543-50.

2. George B, Bresson D, Bouazza S, Froelich S, Mandonnet $\mathrm{E}$, Hamdi $\mathrm{S}$ et al. Les chordomes. Neurochirurgie $2014 ; 60$ (3) : 63-140

3. Guirat A, Affes N, Boujlbene S, Abbes K, Gouiaa $\mathrm{N}$, Daoud $\mathrm{H}$ et al. Chordome sacré : une tumeur fessière rare. Annales de dermatologie et de vénéréologie 2009 ; 136 (6-7) : 526-9

4. Darmoul M, Saad J, Kermani N, Toumi K, Hattab $\mathrm{N}$ et al. Chordome sacré à propos de 5 cas. Neurochirurgie 2011; 57 (4-60): 294

5. Dauty M, Fame A, Le Neels JC, Moreau A, Dubois $C$. Chordome sacré : une pathologie rare. Annales de Réadaptation et de Médecine Physique 2000 ; 43(2) : Pages 84-8

6. Su WP, Louback JB, Gagné EJ, Scheithauer BW. Chordoma cutis: a report of nineteen patients with cutaneous involvement of chordoma. J Am Acad Dermatol 1993; 29: 63-6.
7. Ey Henri, Bernard Pierre, Brisset B. (1989) Manuel de psychiatrie. Paris, Masson, 6e éd. revue et corrigée

8. Sireling Li, Paykel Es, Freeling P et al. (1985) « Depression in general practice. " $\mathrm{Br}$. J. Psychiatry $147: 113-119$

9. Hinkle L. E. \& Wolf H. G. (1958) "Ecologic investigation of the relationship between illness, life experiences and the social environment". Ann. Intern. Med, 49 : 1372-1388. (1957) "Health and the social environment", In Alexander Leigthon, John Clausen, Robert N. Wilson (eds) Exploration in social Psychiatry. New York, Basic Books : 105-132.

10. Ader R., Cohen N. \& Felten D. (1995) "Psychoneuroimmunology: interactions between the nervous system and the immune system". Lancet 345 : 99-103

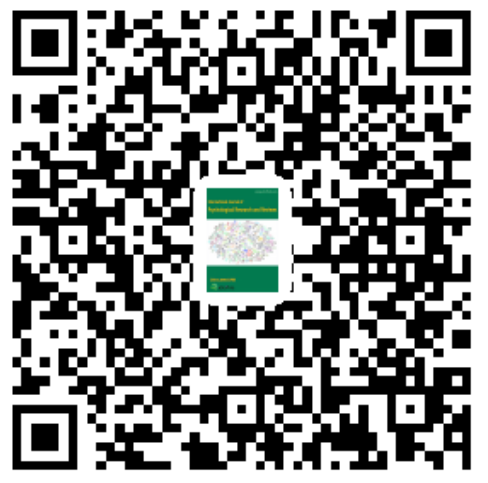

